\title{
INJURY ASSESSMENT OF ANTERIOR TALOFIBULAR LIGAMENT IN KARATE ATHLETES
}

\section{Taskova, Stoyan Rusev, Dimitar Ganchev}

Abstract: This research is a systematic study of 30 Shotokan karate athletes in the period August 2016 - May 2017. The purpose of the research is to trace the dependency between the fighting stance and the dominant limb of the athlete compared to the percent of athletes with anterolateral instability of the ankle joint. The used research methods include: modified questionnaire containing 52 questions on the health status of the athletes, created by us questionnaire for determining the fighting stance and the dominant limb, imaging diagnostic through stress-radiography, provocative clinical "anterior drawer" tests and "talar tilt test".

. Data analysis show high percent of affection of anterior talofibular ligament of right ankle joint with registered right dominant limb and the fighting stance.

Key words: anterolateral instability, ankle instability, Shotokan, provocative clinical tests, the fighting stance ankle instability, Shotokan, karate athletes, fighting stance, diagnostic imaging

\section{Introduction}

Ankle joint ligament injuries as a result of spraining are most frequently seen injuries of the musculoskeletal system. Each year about half a million ankle sprains require visits to the emergency wards in the USA. Published data show that more of the half of all people with ankle sprain do not seek specialist care. That way the real frequency of injury can be much greater (McKeon, Wikstrom, 2015).

Jennifer M. et al. show five types of sports as most risky: basketball, volleyball, football, soccer, lacrosse (McKeon, Wikstrom, 2015). Although karate does not belong to the above listed types it is of the sports requiring quick changes of directions, jumping and kicking. After analyzing the mechanism of injury and the condition of the injured ankle joint in particularly injury of the anterior talofibular ligament referred to the fighting stance, we think that this gives possibility for grading the risk assessment and determining the specific preventive program, compliant with the specific nature of this sport.

About $80 \%$ of ankle ligament lesions are caused by forced supination (supination inversion type), during which the lateral ligaments are injured to a different degree: lig. talofibulare ant (ALTF), lig. calcaneofibulare (LCF) et lig. talofibulare post. (PLTF), as well as anterolateral joint capsule. Pronation injuries with abduction of the foot base or eversion of the tip of the same are much rarely seen and in them the deltoid ligament is injured. Bigger pronation load can lead to a rupture of tibiofibular syndesmosis (Shoylev, 1983).

In great number of the cases the lateral ankle sprains have very high percent of recurrences $(30 \%$ to $40 \%$ ) and many of the patients develop chronic ankle instability (McKeon, Wikstrom, 2015).

\section{Purpose}

To trace the dependence between the fighting stance and the dominant leg of the athlete compared to the percent of the athletes with anterolateral instability of ankle joint.

\section{Characteristic of the tested people}

A population of 30 karate athletes was followed-up, 24 of them men and 6 women (fig.1). The average values of the indexes are: age - 25.86 years, height $176 \mathrm{~cm}$ and weight $73.43 \mathrm{~kg}$.

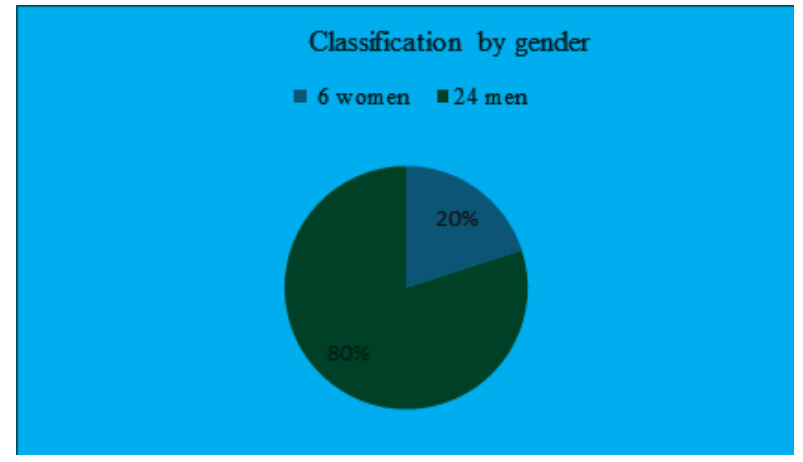

Figure 1. Classification by gender.

Organization of the study 
For the period August 2016 - May 2017 in the University Multi-Profile Hospital for Active Medical Treatment and Emergency „N.I. Pirogov” clinical trials of 30 karate athletes with the medical history of ankle joint instability were carried out.

\section{Methods}

- Modified questionnaire for the health status of the athletes which included 52 questions (Brukner, Khan, 2007). It was drawn up by the Medical Committee of the Bulgarian Shotokan Karate Federation (BSKF). Some of the questions give information about the history of ankle joint injury.

- Created by us questionnaire for identifying the fighting stance and the dominant limb.

- Provocative anterior drawer test тест. Таlus moves forward with fixed tibia. Above 10 $\mathrm{mm}$ or difference of $3 \mathrm{~mm}$ contralateral injury of ATFL was also observed (Penev and Others, 2012).

- Provocative talar tilt test. The tilt test was done with inversion and eversion of the ankle joint from neutral position. The normal limits are from $5^{0}$ to $23^{\circ}$. With more than $23^{\circ}$ or difference of $5^{0}$ contralateral injury of ATFL was observed (Penev et al, 2012). The provocative tests were applied before stress-radiography of both ankle joints.

- Imaging diagnostic - Stress-radiography was administered by traumatologist and radiologist and the data were objectified with $\mathrm{x}$-ray images with recorded tilt degrees of the talus and distance between the tibia and talus in millimeters for left and right ankle joint. According to data from other authors (Penev at al, 2012), when reading the tibiotalar angle bigger than $10^{\circ}$ and difference bigger than $5^{\circ}$ compared to contralateral ankle anterolateral ankle instability was found.

(http://www.su-varna.org/izdanij/Medicina-2-12/ pages29 32.pdf1' (available on 30 May 2017)

\section{Results}

1. Stress radiography results among tested people $67 \%$ of the cases were identified as stable and 33\% of the cases as instable (figure 2).

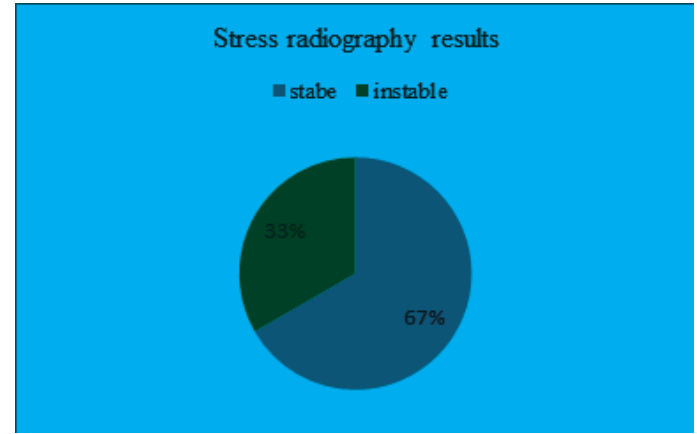

Figure 2. Stress radiography results.

2. The analysis of the stress radiography results show that $43 \%$ of all the tested people have injury of anterior talofibular ligament (figure 3). Of them $62 \%$ are on right ankle and $38 \%$ on left ankle (figure 4).

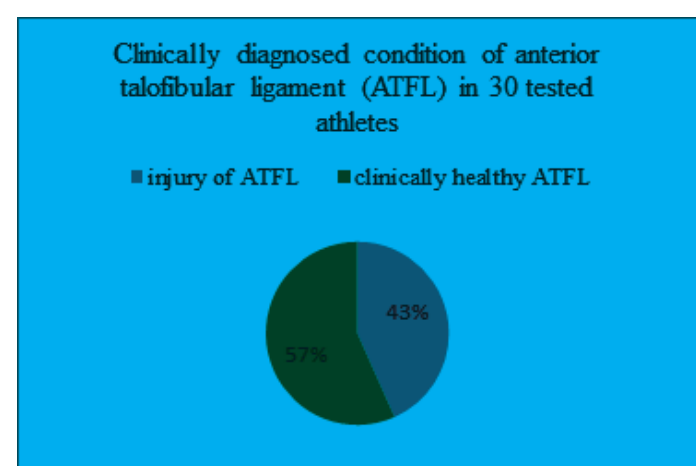

Figure 3. Clinically diagnosed condition of anterior talofibular ligament (ATFL) in 30 tested athletes.

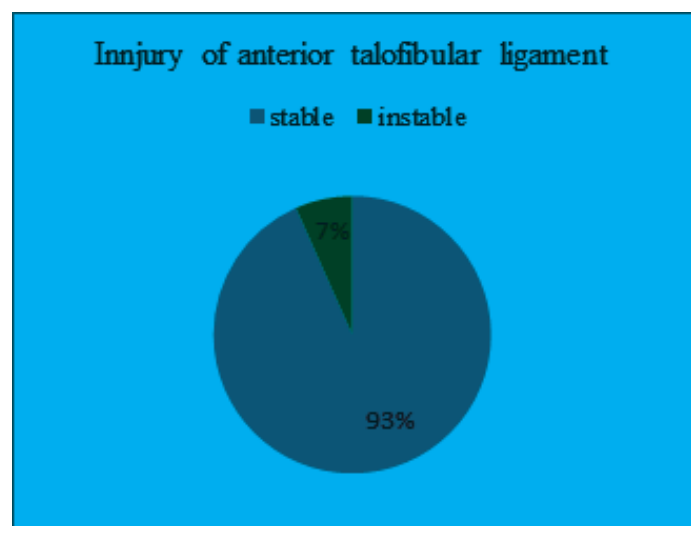

Figure 4. Injury of anterior talofibular ligament.

3. The anterior drawer and talar tilt functional tests were performed before stress radiography by a traumatologist. The preliminary testing of ankle joint instability through these tests gave a result which was proven by means of radiography in $93 \%$.

4. The analysis of the results from the questionnaire for the dominant limb and the guard used in the game - $90 \%$ of the athletes determine as 
dominant their right limb, $10 \%$ the left one (figure 5). In accordance with the fighting stance $-83 \%$ use left fighting stance and $17 \%$ right fighting stance (figure 6).

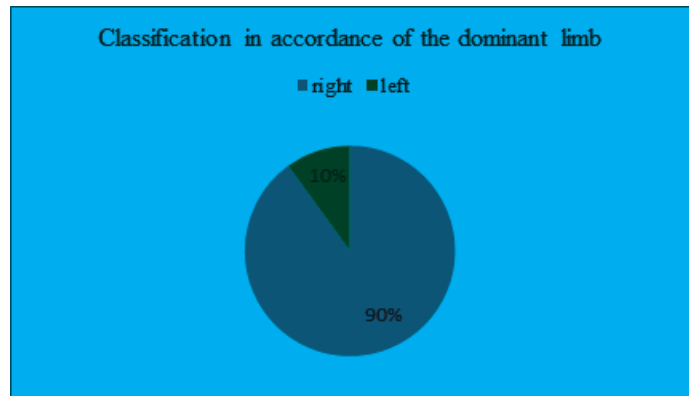

Figure 5. Classification in accordance of the dominant limb.

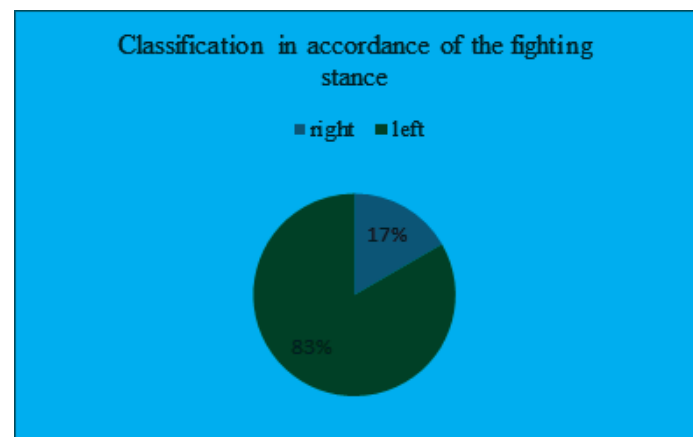

Figure 6. Classification in accordance of the guard used.

5. In $47 \%$ of all the tested people right ankle joint is the most often injured one (figure 7). This result compared with the guard used and the dominant limb shows that according to the fighting stance the right ankle joint is in position of biggest loading and is determining for the rapid movement, the abrupt change of direction when moving and for kicking because it is dominant according to the received tests.

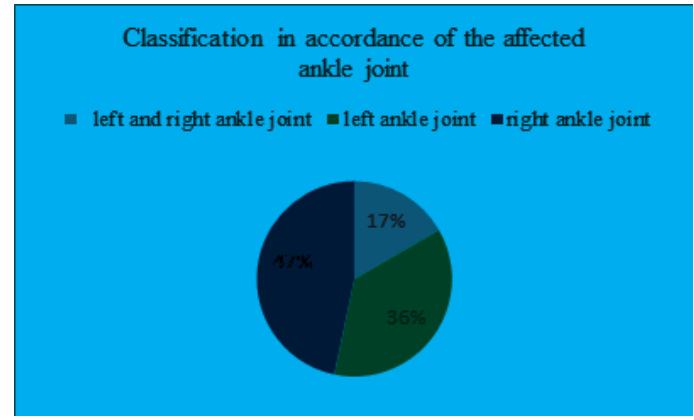

Figure 7. Classification in accordance of the affected ankle joint.

\section{Discussion}

The lack of data about traumatism of ankle joint in karate athletes is the main reason for the performed study. Karate does not fall into the classification of the riskiest sports for ankle joint injuries, but the analysis of the received by us results shows that the main group of athletes undergo trauma of this joint. We were interested in using an algorithm for determining the stability of the joint and to register the affection of anterior talofibular ligament. The correlation with the fighting stance the dominant limb would give an idea for the most frequently affected ankle joint in accordance of the type of play and competitive sport technique. This would put a good foundation for risk assessment for future injuries and a possibility for establishing a preventive program. On the basis of this research, a number of analyses are to be made of the ability to balance, using a tensiometric platform and functional kinesitherapeutic tests.

\section{Acknowledgements}

We would like to thank the athletes from the $\mathrm{Na}$ tional team on Shotokan karate for their assistance and patience during the tests.

Thanks to the management of the NSA "Vassil Levski” for their support during this study.

Thanks to the team from Institute "N.I. Pirogov" for their assistance.

\section{Literature}

Brukner P., Khan K., Clinical sports medicine 3E, McGRAW-HILL Professional, 2007, p. 949-953

McKeon, P. Wikstrom E. (2015), Quick questions in ankle sprains: expert advice in sports medicine, NJ: SLACK Incorporated, Thorofare

Penev Pr., Raykov D., Simeonova V., Introducing ultrasound diagnostic for testing anterior talofibular ligament. Bulletin of the scientists union - Varna, 2012, volume XVII, 29-32., http://www.su-varna.org/izdanij/ Medicina-2-12/pages29 32.pdf

Shoylev D., Sports traumatology, Sofia, 1983, p.155

Veselina Taskova, PhD

Department of Theory and methodology of kinesitherapy

"Vassil Levski" National Sports Academy

Sofia 1000, № 1 Gurgulyat str

Phone number: +359898592031

Email: veselina taskova@abv.bg

Dimitar Ganchev, Associate Professor

Department of Theory and methodology of kinesitherapy

Vassil Levski National Sports Academy

Sofia 1000, № 1 Gurgulyat street

Phone number: +359892299790

Email: dimigan@mail.bg

Stoyan Rusev S, M.D., PhD

UMHAMTE „N. I. Pirogov” EAD

Sofia 1000, Blvd. Totleben № 121

Phone number:+35929154256

Email: dl_100@abv.bg 